\title{
Improving the methods of organizational and technological design in the reconstruction of health facilities
}

\author{
Konstantin Lyakhovsky ${ }^{*}$, and Alexander Arkhipov \\ Moscow State University of Civil Engineering, 129377, Moscow, Russia
}

\begin{abstract}
Construction work in the conditions of existing health facilities requires compliance with increased requirements, which imposes additional restrictions on the application of known organizational and technological solutions, which in turn create a need to develop new or improve existing methods of organizational and technological design in the reconstruction of health facilities. In the development of organizational and technological documentation, it is necessary to take into account the fact that medical facilities are not classified as production facilities, although the restrictions for this type of facilities are very significant. The aim of the work is to improve the accuracy of calculations when planning the finishing (plaster) work in terms of labor costs. As a result of the study, based on the initial data, factors describing the limited workplace were identified, which will allow in subsequent studies to justify an increase in labor costs (reduced productivity) for working conditions in a limited space during the reconstruction of health facilities.
\end{abstract}

\section{Introduction}

In the conditions of the current dense urban development, the existing buildings of medical facilities are being reequipped with a change in the functional purpose of the medical departments located in them, creating more comfortable conditions for patients and visitors to stay. Before the reconstruction work, a lot of work is being done to develop new standards for general technical solutions used in the work, the issues of interiors, the improvement of the surrounding area for children's and city clinics, stationary health facilities in the city of Moscow within the framework of urban development programs and national projects.

Large-scale work was carried out during the implementation of the State program of the city of Moscow "Development of health care in the city of Moscow (Metropolitan health care)". The targeted investment program was designed for work in 2011-2020. During this period, there was a significant increase in the volume of reconstruction of existing

\footnotetext{
*Corresponding author: aljurgaitis@gmail.com
} 
healthcare facilities, including due to the modernization of existing buildings, in comparison with the volume of similar work in previous years. $[4,13,14,20,21,24]$

In the reconstruction of the facilities there is a need to perform a set of works not inherent in the new construction, such as dismantling the structures and strengthening them, replacing individual structural elements, dismantling structures, redevelopment and installation of new premises. The peculiarity of the demolition of works and work to strengthen the structures is that they are almost always accompanied by a set of works to ensure the stability of the preserved parts of the buildings and reinforced structures. These works can be carried out in the conditions of the operating facility, which makes it difficult to mechanize them. At the same time, the main means of installation are the simplest installation devices - winches, hoists, polyspastes, jacks, mounting beams, which leads to significant unproductive labor costs in the organization of jobs and increased labor costs in the process of work. [26]

Special kind includes work on changing the geometric parameters of structures without dismantling existing structures: changing the pitch of columns, spans, selective replacement of individual structural elements. The limited height and planned dimensions of the building in most cases exclude the possibility of installation cranes, and technologically specialized complexes of machines and devices for these types of work are currently insufficient. [1]

When choosing the method of reconstruction, the following features are taken into account: when the buildings are fully reconstructed, the new buildings are erected on the site of old ones or the new structures are installed behind the size of the existing building, which allows the use of the latter as an installation site, i.e. the production of works is not constrained by the process; in medium and small reconstruction, the preference is given to solutions that allow for continuity or minimal shutdown of the process and the maximum preservation of existing structures, but it is necessary to take into account the possibility of performing work in specific conditions of the medical facility. Technical solutions should be based on the results of a survey of designs that require specially trained personnel and equipment and can be long-lasting and costly. [1]

Another feature of the reconstruction of existing medical facilities is the proximity to the operating facilities located in the territories of large hospitals, or located near residential buildings, which reduces compared to the new construction "in a clean field" productivity of workers by $25 \ldots 30 \%$ due to the large number of forced downtime, increasing the distance of delivery of materials, the inability to use certain types of equipment, the difficulty of performing complex work on the replacement of structures, the share of wages increases by $30-45 \%$, the costs of mechanization means increase, the unit cost of certain types of work increases, labor costs increase over time. [2]

When creating modern conditions for patients' stay in medical facilities, there is a need to set up comfortable hospital wards in existing areas, additional bathrooms, technical rooms for placing, if necessary, additional climate and other equipment, and other premises for various purposes of a small (up to $10.5 \mathrm{~m}^{2}$ ) area. The total area of small-volume premises in the total area of buildings in existing facilities is already about $20-25 \%$, and during reconstruction (modernization), the percentage of such premises can increase to 30$50 \%$. [15]

In the conditions of ever-changing requirements for the provision of medical services, comfortable conditions of stay of patients and visitors, as well as taking into account the lifespan of facilities in health care, it is necessary to constantly improve the logistics by carrying out not only the regulatory works that are carried out during the operation of such facilities, but also the timely work on reconstruction and modernization of facilities. [23]

In the process of carrying out work in an environment where the volume of reconstruction of health facilities is only increasing, as well as changing the requirements 
for the provision of medical services to the population of the city, there is a need to evaluate and analyze existing methods of organizational and technological design in the reconstruction of existing health facilities, and when organizing such works in a limited space, there is a need to improve existing methods. [10, 11, 12, 13, 15, 16, 17 -19]

\section{Materials and methods}

The study conducted standard procedures for analysing data on the distribution of the types of work that have the most significant impact on the duration of work in the reconstruction of health facilities, obtained from the design and executive documentation for the reconstruction of the facilities. As a result of the analysis of the data obtained from the organizational and technological documentation of 250 completed health facilities, it was substantiated that during the reconstruction of such facilities, the share of finishing (including plaster) works sometimes makes up $80 \%$ of all construction and installation work at the site. Thus, it may be assumed that the performance of this type of work may have the greatest impact on the duration and timing of the reconstruction of health facilities. The study of the problems arising in the planning of this type of work, will be continued.

Also, during the study of the raw data, the analysis of the design documentation, on the basis of which the organizational and technological design is carried out, identified the most common types of premises arranged during the reconstruction (capital repair) of health facilities. According to the data indicated in the design documentation of most institutions, the share of small space premises (physical space) up to $10.5 \mathrm{~m}^{2}$ sometimes makes up $50 \%$ of the total number of premises and up to $30-40 \%$ of the space of the reconstructed buildings. At the same time, it is worth paying attention to the difference of elevation marks in rooms with different indicators in area. The difference in elevation marks in the premises, adopted in the design of the reconstruction of the health facility, is most often explained by the functional purpose of the premises, the location of these premises, as well as due not only to elevation (constructive) marks of the premises, but also the possible laying of engineering communications under the ceiling in trays or boxes. [8, 9]

The data of the research can be considered on the example of a fragment of the specification of the premises, given in Table 1, obtained from the design documentation for the reconstruction of the building No. 2 of the state budgetary institution "The Blood Transfusion Station of the Moscow Healthcare Department", at: 125284, Moscow, Polykarpova Street, 14, Bld. 2. It should be noted that this medical institution does not provide medical services to critically ill patients, but is a specialized institution, nevertheless, general-purpose premises and their functional use are the same as in large inpatient or outpatient facilities.

Table 1.

\begin{tabular}{|l|c|c|c|}
\hline No. & Name & Area, $\mathrm{m}^{2}$ & Finished height, $\mathrm{m}$ \\
\hline 001 & Stairs & 10.16 & 3.00 \\
\hline 002 & Bathroom & 10.09 & 3.00 \\
\hline 003 & Storage room & 3.10 & 2.80 \\
\hline 004 & Changing room & 26.17 & 2.80 \\
\hline 005 & Dressing room & 25.83 & 3.00 \\
\hline 006 & Dressing room & 26.09 & 3.00 \\
\hline 007 & Corridor & 83.24 & 2.80 \\
\hline 008 & Shower & 24.80 & 3.00 \\
\hline
\end{tabular}




\begin{tabular}{|c|c|c|c|}
\hline 009 & $\begin{array}{c}\text { Dressing room for } \\
\text { outerwear }\end{array}$ & 23.65 & 2.80 \\
\hline 010 & Dressing room & 23.49 & 2.80 \\
\hline 011 & Laundry & 7.31 & 2.80 \\
\hline 012 & Dressing room & 25.41 & 2.80 \\
\hline 013 & Wash-stand & 4.72 & 3.00 \\
\hline 014 & Bathroom & 4.29 & 3.00 \\
\hline
\end{tabular}

* Project data are shown in part.

The data from the specification fragment shows that 6 out of 14 premises, or $43 \%$ of the number of premises, have an area of less than $10.5 \mathrm{~m}^{2}$. The total number of premises in the reconstructed building is 81 , the total area of premises is $1420.09 \mathrm{~m}^{2}$, of which smallspace premises make up $52 \%$ of the number of premises, and $35 \%$ of the area of premises. The most interesting thing in this study is the organizational and technological section of the design documentation, namely the Construction Organization Project, which calculates the need for workforce during work, which will be considered on two examples.

\section{Example 1.}

The number of employees and engineering and technical workers is:

where

$$
A=\frac{C I W}{(n * W * T)}
$$

$C I W$ - total cost of construction and installation work (421,318 rubles);

$W$ - average output per month per worker (330,000 rubles);

$T$ - duration of work in months ( 9 months per object analogue);

$n$ - number of shifts ( 2 shifts per object analogue);

$A$ - number of people* (71 - calculated value). [8]

\section{Example 2.}

The average number of $N$ workers employed in construction and installation work is determined by the formula:

where

$$
N=\frac{T_{P}}{T_{n} \times 167}
$$

$T_{p}$ - labor costs for construction and installation work, man-hour (30060);

$T_{n}$ - duration of work in months ( 9 months for an analogue object);

167 -average monthly number of working hours;

$N$ - number of people ** (20 people - estimated value). [9]

Particular attention should be paid to the fact that the reconstruction of the facilities (their part within the campus, or separate premises), are carried out on the terms of the execution of the state order (state assignment), that is, are regulated by the Federal Law of 05.04.2013 N 44-FL (ed. from 27.12.2019) "On the contract system in the procurement of goods, works, services for the provision of public and municipal needs" (ed. from 27.12.2019, with amendments and additions, entered into force from 08.01.2020, further 44 Federal Law). In accordance with article 24 of 44 Federal Law, the procurement documentation separately identifies the object of purchase, the initial (maximum) price of the contract and its justification under article 22 of this federal act, the amount of enforcement of the application for the purchase (if the requirement for the application is established by the customer), the terms and conditions of delivery of the goods, the performance of work or the provision of the service, the size of the enforcement of the contract. Thus, before deciding to participate in the auction, the general contractor needs to work out in detail the issues of organizing the construction process. In the development of organizational and technological documentation, in addition to the main issues of construction production, it is necessary to take into account the fact that the reconstruction 
of health facilities, for the most part, is carried out in the conditions of existing institutions, that is, the work can be carried out on one or more floors (in the offices) of buildings in which medical activities are still carried out. The result of organizational and technological documentation should be developed as balanced organizational and technological solutions to implement the project. [22].

*According to the project. The existing state budgetary institution "City Clinical Hospital named after I.V. Davydovsky of the Moscow Healthcare Department". The calculation is made for the object as a whole, the project provides for work on three floors of the building with an area of $3200 \mathrm{~m}^{2}$.

** According to the project. The existing "Blood Transfusion Station of the Moscow Healthcare Department". The calculation is made for the object as a whole, the project provides for work with an area of $1420.09 \mathrm{~m}^{2}$. The distribution of workers in categories is accepted: workers - $84.5 \%$, engineering and technical workers - $11 \%$, employees $3.2 \%$, junior maintenance staff and security $-1.3 \%$.

Based on paragraph 5.6 paragraph 9 "JV 48.13330.2011. A set of rules. Construction organization. The updated edition of SNIP 12-01-2004" (by order of the Russian Ministry of Regional Affairs of 27.12.2010 N 781, ed. from 26.08.2016) before the start of work on the site, the contractor carrying out the construction, develops organizational and technological documentation.

The organizational and technological documentation developed by the contractor includes clause 5.7.2 "BC 48.13330.2011. Code of rules. Organization of construction. Updated version of BC 12-01-2004" (approved by Order of the Ministry of Regional Development of the Russian Federation of December 27, 2010 N 781, revised on 26.08.2016):

$\checkmark$ work projects;

$\checkmark$ schemes and instructions for the production of works;

$\checkmark$ quality control schemes

$\checkmark$ flow charts;

$\checkmark$ main provisions for the production of construction and installation work as part of the working documentation of model mass-use projects;

$\checkmark$ other documents containing decisions on the organization of construction production and construction and installation technology, issued, approved and registered in accordance with the rules in actual in the organizations developing, approving and coordinating these documents.

\section{Results}

The lack of a full-fledged design solution due to the lack of a regulatory framework for the development of projects for the reconstruction of buildings, brought to the fore the work of the general contractor, who has to develop organizational and technological documentation. The study found that with the same amount of time for work taken on analogues, various indicators of construction cost, and other design data, which have a significant impact on the conditions of work in the performance of the State order, as well as having general data on the work in the form of the specification of premises, trim statements, it is impossible to use the methodology used by the project organizations to calculate labor costs. For medical institutions, the cost of labor should be calculated and planned by premises, as, in practice, there is a number of other factors in the work, which also affect the timing of the reconstruction of health facilities, for example, the storage of materials and structures on the street is not provided. All materials after unloading are immediately submitted to the place of work, which further limits the space for work inside the reconstructed buildings. $[8,25]$ 
When planning the reconstruction of the facilities, as well as making organizational decisions, the general contractor needs to have a numerical description of the scope of work, which can be presented in table form. To describe the scope of work (SW) in Table 2 , calculations are made of the ratios of the plastered area of vertical surfaces (walls) to the floor area in the room, without taking into account the number of working, changeable and other factors at a given height of the plastered surface of $\mathrm{h}=2.800 \mathrm{~m}$. Similar calculations have been made for other heights, which are often found in these works in the premises of existing medical institutions.

Table 2.

The ratio of the area of the plastered surface of the walls at the height of the room $\mathrm{h}=2.80 \mathrm{~m}$ to the floor area

\begin{tabular}{|c|c|c|c|c|c|c|c|c|c|}
\hline Dimensions & $\mathbf{1 . 5 0}$ & $\mathbf{1 . 8 0}$ & $\mathbf{2 . 1 0}$ & $\mathbf{2 . 4 0}$ & $\mathbf{2 . 7 0}$ & $\mathbf{3 . 0 0}$ & $\mathbf{3 . 3 0}$ & $\mathbf{3 . 6 0}$ & $\mathbf{3 . 9 0}$ \\
\hline $\mathbf{1 . 5 0}$ & 7.467 & 6.844 & 6.400 & 6.067 & 5.807 & 5.600 & 5.430 & 5.289 & 5.169 \\
\hline $\mathbf{1 . 8 0}$ & 6.844 & 6.222 & 5.778 & 5.444 & 5.185 & 4.978 & 4.808 & 4.667 & 4.547 \\
\hline $\mathbf{2 . 1 0}$ & 6.400 & 5.778 & 5.333 & 5.000 & 4.741 & 4.533 & 4.364 & 4.222 & 4.103 \\
\hline $\mathbf{2 . 4 0}$ & 6.067 & 5.444 & 5.000 & 4.667 & 4.407 & 4.200 & 4.030 & 3.889 & 3.769 \\
\hline $\mathbf{2 . 7 0}$ & 5.807 & 5.185 & 4.741 & 4.407 & 4.148 & 3.941 & 3.771 & 3.630 & 3.510 \\
\hline $\mathbf{3 . 0 0}$ & 5.600 & 4.978 & 4.533 & 4.200 & 3.941 & 3.733 & 3.564 & 3.422 & 3.303 \\
\hline $\mathbf{3 . 3 0}$ & 5.430 & 4.808 & 4.364 & 4.030 & 3.771 & 3.564 & 3.394 & 3.253 & 3.133 \\
\hline $\mathbf{3 . 6 0}$ & 5.289 & 4.667 & 4.222 & 3.889 & 3.630 & 3.422 & 3.253 & 3.111 & 2.991 \\
\hline $\mathbf{3 . 9 0}$ & 5.169 & 4.547 & 4.103 & 3.769 & 3.510 & 3.303 & 3.133 & 2.991 & 2.872 \\
\hline $\mathbf{4 . 2 0}$ & 5.067 & 4.444 & 4.000 & 3.667 & 3.407 & 3.200 & 3.030 & 2.889 & 2.769 \\
\hline $\mathbf{4 . 5 0}$ & 4.978 & 4.356 & 3.911 & 3.578 & 3.319 & 3.111 & 2.941 & 2.800 & 2.680 \\
\hline $\mathbf{4 . 8 0}$ & 4.900 & 4.278 & 3.833 & 3.500 & 3.241 & 3.033 & 2.864 & 2.722 & 2.603 \\
\hline $\mathbf{5 . 1 0}$ & 4.831 & 4.209 & 3.765 & 3.431 & 3.172 & 2.965 & 2.795 & 2.654 & 2.534 \\
\hline $\mathbf{5 . 4 0}$ & 4.770 & 4.148 & 3.704 & 3.370 & 3.111 & 2.904 & 2.734 & 2.593 & 2.473 \\
\hline $\mathbf{5 . 7 0}$ & 4.716 & 4.094 & 3.649 & 3.316 & 3.057 & 2.849 & 2.679 & 2.538 & 2.418 \\
\hline $\mathbf{6 . 0 0}$ & 4.667 & 4.044 & 3.600 & 3.267 & 3.007 & 2.800 & 2.630 & 2.489 & 2.369 \\
\hline $\mathbf{6 . 3 0}$ & 4.622 & 4.000 & 3.556 & 3.222 & 2.963 & 2.756 & 2.586 & 2.444 & 2.325 \\
\hline $\mathbf{6 . 6 0}$ & 4.582 & 3.960 & 3.515 & 3.182 & 2.923 & 2.715 & 2.545 & 2.404 & 2.284 \\
\hline $\mathbf{6 . 9 0}$ & 4.545 & 3.923 & 3.478 & 3.145 & 2.886 & 2.678 & 2.509 & 2.367 & 2.247 \\
\hline $\mathbf{7 . 2 0}$ & 4.511 & 3.889 & 3.444 & 3.111 & 2.852 & 2.644 & 2.475 & 2.333 & 2.214 \\
\hline $\mathbf{7 . 5 0}$ & 4.480 & 3.858 & 3.413 & 3.080 & 2.821 & 2.613 & 2.444 & 2.302 & 2.183 \\
\hline $\mathbf{7 . 8 0}$ & 4.451 & 3.829 & 3.385 & 3.051 & 2.792 & 2.585 & 2.415 & 2.274 & 2.154 \\
\hline $\mathbf{8 . 1 0}$ & 4.425 & 3.802 & 3.358 & 3.025 & 2.765 & 2.558 & 2.388 & 2.247 & 2.127 \\
\hline $\mathbf{8 . 4 0}$ & 4.400 & 3.778 & 3.333 & 3.000 & 2.741 & 2.533 & 2.364 & 2.222 & 2.103 \\
\hline $\mathbf{8 . 7 0}$ & 4.377 & 3.755 & 3.310 & 2.977 & 2.718 & 2.510 & 2.341 & 2.199 & 2.080 \\
\hline
\end{tabular}




\begin{tabular}{|c|l|l|l|l|l|l|l|l|l|}
$\mathbf{9 . 0 0}$ & 4.356 & 3.733 & 3.289 & 2.956 & 2.696 & 2.489 & 2.319 & 2.178 & 2.058 \\
\hline $\mathbf{9 . 3 0}$ & 4.335 & 3.713 & 3.269 & 2.935 & 2.676 & 2.469 & 2.299 & 2.158 & 2.038 \\
\hline $\mathbf{9 . 6 0}$ & 4.317 & 3.694 & 3.250 & 2.917 & 2.657 & 2.450 & 2.280 & 2.139 & 2.019 \\
\hline $\mathbf{9 . 9 0}$ & 4.299 & 3.677 & 3.232 & 2.899 & 2.640 & 2.432 & 2.263 & 2.121 & 2.002 \\
\hline $\mathbf{1 0 . 2 0}$ & 4.282 & 3.660 & 3.216 & 2.882 & 2.623 & 2.416 & 2.246 & 2.105 & 1.985 \\
\hline
\end{tabular}

In the course of the study, based on the current regulatory documentation, the work front coefficient-K was calculated, which will later be used in the calculation of labor costs for premises, as well as the calculation of labor costs, reduced to the unit area of the room for the specified (design) dimensions of the premises. There is a correlation between the scope of work coefficient and labor costs, which can be considered in Chart 3.

\section{Chart 3.}

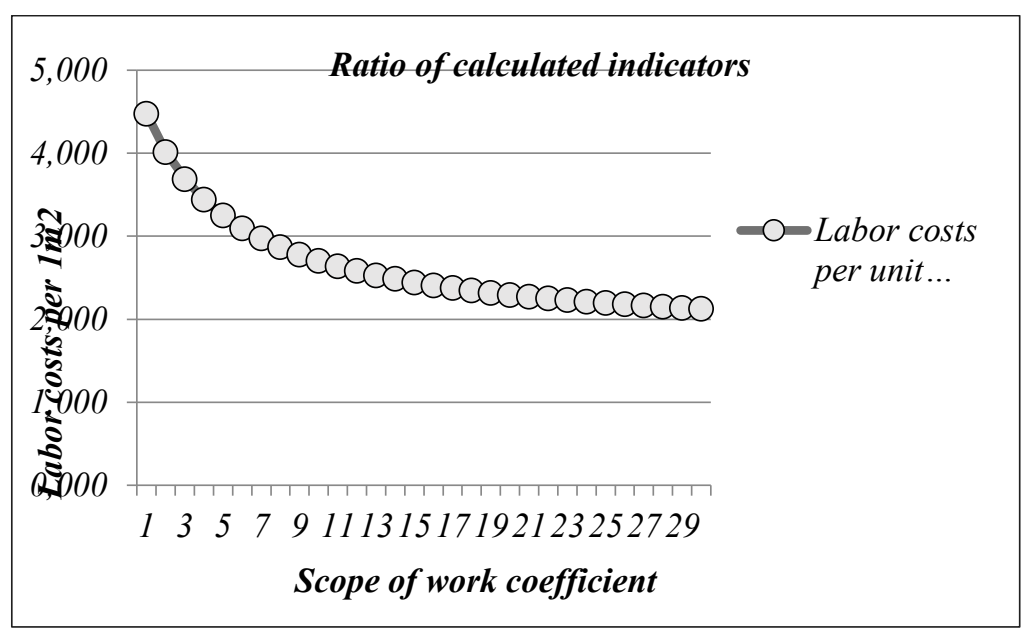

\section{Discussion}

According to the data obtained as a result of the study, based on the initial data and calculations, a standard procedure is performed for calculating indicators describing the reliability of the dependence, that is, the value of the predicted deviation of the calculated (theoretical) value from the quantitative measurements obtained in fact. To do this, the following correlation coefficients were calculated according to Student, Fisher, Kolmogorov (Pearson, Spearman). The predicted deviation does not exceed 5\%.

The labor costs of workers directly involved in construction and installation work in a limited space, at this stage of the study can be calculated by the formula:

$$
R_{\text {total }}=R_{1}+R_{2}+\ldots+R_{n}
$$

where

$R$ - labor costs of workers per $1 \mathrm{~m}^{2}$ of floor indoors $1,2,3-\mathrm{n}$;

$$
\boldsymbol{R}=\boldsymbol{F}(\boldsymbol{k}) * \boldsymbol{N}
$$

$K$-coefficient of scope of work in the premises;

$N$-standard labor costs according to the State Elemental Estimated Standards. 
In further work on the research topic, to improve the accuracy of calculations for the time and number of workers on the construction site, it is planned to calculate the maximum concentration of workers during the reconstruction of health facilities. Conducting research on this topic will allow, in the absence of completeness and reliability of information about the object where reconstruction work is planned, to apply mathematical methods to solve problems of forecasting, planning, operational management and control, as well as to solve the following problems:

$\checkmark \quad$ choosing the best option among the others;

$\checkmark$ predicting process and risk development;

$\checkmark \quad$ finding a possible solution to a complex problem [3];

$\checkmark \quad$ determining the actual (real) time of the work;

$\checkmark \quad$ determining the optimal organizational scheme for project management. [18]

\section{Conclusions}

This study presents the existing methods of organizational and technological design when carrying out work on the reconstruction of health facilities, and also considers the possibilities for improving such methods using new and existing indicators. Already at this stage of the research, we can build an information model for which the calculation of labor costs required for the work will be performed. The obtained data show that using the calculation based on the K-coefficient of the work front describes the limitations of the workplace (also known as the scope of work coefficient) reflects the conditions of work production and allows us to find an increase in labor costs (decrease in productivity) for working conditions in a limited space. The discrepancy between the design and actual duration values makes it necessary to take into account the number of rooms with a limited volume, in which labor costs significantly increase, when developing working documentation. Solving research problems will increase the efficiency of production organization in the construction (re-construction) of buildings and structures in the conditions of existing health facilities.

\section{Glossary}

The scope of work is referred to object under construction and is necessary to accommodate a certain number of workers with equipment required to perform a given task $[5,6]$

Building modernization is a special case of reconstruction that involves changing and updating the space-planning and architectural solutions of an existing old building and its outdated engineering equipment in accordance with the requirements of current standards for the aesthetics of medical services and operational parameters of administrative buildings and medical buildings located at the territory of hospital.

A workplace is a space within which the workers involved in the construction process move, where objects of labor, tools, devices, and products are located. [6]

\section{References}

1. M.N. Yershov, A.A. Lapidus, Modern technologies of reconstruction of civil buildings (Publisher: ASV, Moscow, 2014).

2. P.P. Oleynik, V.I. Brodsky, Features of the organization of construction production in the reconstruction of buildings and structures, Technology and organization of construction production, 4, 40-45 (2013). 
3. T.Ya. Danelyan, Formal methods of expert assessments, Economics, statistics and Informatics, 1, 183-187 (2015).

4. A.E. Prokopenko, Interview. "Production and Technical Association of Capital Repairs and Construction: working ahead of the curve". [E-resource] URL: http://mdpr.ru/ptokris-rabota-na-operezhenie publication date: 12.08.2014 (date of access: 20.01.2020)

5. According to the resource: http://stroy-machines.ru/content/view/129/83/

6. Terminological dictionary of construction in 12 languages, [E-resource] URL: https://technical_translator_dictionary.academic.ru/263804 (date of access: 20.01.2020)

7. Unified information system in the field of procurement. [E-resource] URL: https://zakupki.gov.ru/epz/order/notice/ok44/view/documents.html?regNumber $=03732$ 00053817000044\&backUrl=e74f233f-44a4-4588-a14b-3d702cbe1ce5 (procedure \# 0373200053817000044 Technical task. Section construction organization Project. Order no. 088 / 17POS (POI). Moscow 2017) (date of access: 21.09.2020)

8. Unified information system in the field of procurement. [E-resource] URL: https://zakupki.gov.ru/epz/order/notice/ea44/view/documents.html?regNumber=03732 00053817000029 (procedure no. 0373200053817000029 Project. part 1, Project. part 2. Section 3. Architectural solutions. RP. Sheet 3. Section 6. The project organization of construction. 0010-14-PZ. Sheet 22) (date of access: 02.11.2020)

9. I.A. Dorogan, Model of organization of the life cycle of a medical building, MGSU Bulletin, 13 (12), 1474-1481 (2018). DOI: 10.22227/1997-0935.2018.12.1474-1481

10. G.G. Malykha, O.B. Guseva, V.V. Petrunin, N.D. Tesler, Carrying out reconstructive works at existing health facilities, MGSU Bulletin, 9, 214-220 (2012).

11. V.M. Kotor, S.I. Ekba, Optimization of organizational and technological solutions with the use of BIM technologies in the renovation of residential buildings, Scientific and technical journal. Construction production, 2, 10-16 (2020).

12. S.A. Andreeva, Urban reconstruction of complexes of buildings of medical institutions in the conditions of formation of urban development. In the collection: PROBLEMS of URBAN RECONSTRUCTION, Collection of articles. Samara State Technical University, Samara, 22-27 (2019).

13. N.D. Tesler, G.G. Malykha, V.V. Petrunin, Factors influencing the formation of spaceplanning solutions for the reconstruction of multifunctional medical facilities, MGSU Bulletin, 9, 48-54 (2012).

14. A.Yu. Yurgaitis, D.Yu. Yurgaitis, Potential of introduction of GPS navigation technology during construction control at capital construction, reconstruction and reprofiling facilities, Scientific and technical journal Construction production, 1, 26-36 (2019).

15. Unified information system in the field of procurement. [E-resource] URL: https://zakupki.gov.ru/epz/order/notice/ok44/view/documents.html?regNumber=03732 00053817000044\&backUrl=e74f233f-44a4-4588-a14b-3d702cbe1ce5 (procedure \# 0373200053817000044 Technical task. Section construction organization Project. Order no. 088 / 17POS (POI). Moscow 2017) (date of access: 21.09.2020).

16. I.A. Dorogan, Influence of organizational and technological complexity on the terms of work execution, MGSU Bulletin, 14 (10), 1331-1340 (2019). DOI: 10.22227/19970935.2019.10.1331-1340

17. K.A. Lyakhovsky, L.L. Sotnikov, Modeling production processes as a tool to solve technological and regulatory problems in construction and utilities / Innovation in the branches of the national economy as a factor in solving the socio-economic problems 
of our time, Collection of reports of the $2^{\text {nd }}$ International scientific and technical conference. Institute of Continuing Education, Moscow State Academy of Public Utilities and Construction, Central Research Institute of Economics and Management in Construction, 165-175 (2012).

18. Guidelines for Design and Construction of Outpatient Facilities. 2018. [E-resource] URL: https://www.fgiguidelines.org/wp-content/uploads/2018/01/FGI-GuildelinesOutpatient-2018_AddRev.pdf (date of access: 07.11.2020)

19. Building Design + Construction. September/October 2020. [E-resource] URL: https://mydigitalpublication.com/publication/?m=46258\&i=674842\&p=14 (date of access: 07.11.2020) p.14-17

20. Reconstruction of health facilities in Gaza is difficult due to lack of materials and funding. Monthly humanitarian Bulletin April 2015. [E-resource] URL: https://www.ochaopt.org/content/reconstruction-health-sector-facilities-gaza-impairedshortages-materials-and-funding

21. An Assessment of Turn-key Contracts for the Realisation of Capital Works Projects Principally for Public Sector Healthcare Facilities by Tony Gibbs BSc DCT(Leeds) FICE FIStructE FASCE FConsE FRSA FRICS November 2008. [E-resource] URL: https://www.paho.org/disasters/index.php?option=com_content\&view=article\&id $=114$ 2:turn-key-projects-can-help-reconstruction-of-health-facilities-inhaiti\&Itemid=0\&lang=en (date of access: 25.09 .2020 )

22. Smart hospitals. Climate Change 2014 Synthesis Report Summary for Policymakers Eresource]

URL: https://www.paho.org/disasters/index.php?option=com_content\&view=article\&id=366 0 :hospitales-inteligentes\&Itemid=911\&lang=en (date of access: 25.09 .2020 )

23. Appendix to the ruling of the Government of Moscow on October 4, 2011. 461- PP State program of the city of Moscow for the medium term (2012-2016) "Moscow City Health Development"

24. The Model Policy for SMART Health Facilities was prepared by Dr. Vasantha Chase, et al, (Castries, Saint Lucia), on behalf of the Pan American Health Organization (2013).

[E-resource]

URL: http://www.saludydesastres.info/index.php?option=com_recursos\&view=\&Itemid $=479$ \&lang=en (date of access: 25.09.2020)

25. Pan American Health Organization. Smart Hospitals Toolkit. Washington, D.C.: PAHO; 2017.1. Safety Management. 2. Maintenance and Engineering, Hospital. 3. Health Facilities. 4. Environmental Monitoring. 5. Environmental Damage Minimization. 6. Relief, Assistance and Protection in Disasters. I. Title. ISBN 978-9275-11939-6 (NLM Classification: WX 150) 